\title{
SUSTAINABILITY IN ACADEMIC COOPERATION: WITHIN AND BEYOND VISEGRAD BORDERS
}

\section{Peter Bielik, VUA President}

\author{
Rector of the Slovak University of Agriculture in Nitra
}

The issues of systematic and purposeful international cooperation are key areas for further development of higher education, supported by a number of positions and policies of the various regional groupings and countries. The Erasmus + programme for the years 2014-2020, is one of the most famous in the conditions of the European Union, focusing on the development and modernization of education, youth and the application of the young generation in the labour market. The issues of scientific research collaboration are addressed by the EU Framework programme for research and innovation. In order to promote the ideas of solidarity and cooperation in the Visegrad region, the International Visegrad Fund promotes various grant schemes and scholarship programmes. The purpose of the fund is to facilitate and promote the development of closer cooperation among citizens and institutions within the region as well as between the $V 4$ region and other countries, especially the Western Balkans and countries of the Eastern Partnership. The fund does so through grant support of common cultural, scientific and educational projects, youth exchanges, cross-border projects and tourism promotion, and through individual mobility programs (scholarships, residencies). Non-governmental organizations (NGOs), civil society organizations (CSOs), municipalities and local or regional governments, schools and universities, but also private companies or individual citizens are eligible for grant support, provided that their projects deal with the region and further develop cooperation among project partners based in the region (Visegrad, 2014).

\section{Initial Aim and Focus: Regional cooperation and sustainability aspects}

The Visegrad University Association (VUA) was established in 2011 within the strategic project "Sustainability in Agrisector of V4 Countries and Cooperating Regions" that the Slovak University of Agriculture coordinated with the support of the International Visegrad Fund. Apart from constituent members, universities and institutions from Thailand, India, Turkey, Moldova, Italy and Germany decided to support the idea of cooperation within the association and currently there are 41 full and 11 honorary members. The main aim of the association is to link partner universities in order to provide quality education and scientific environment and to promote development of closer cooperation among the Visegrad group as well as cooperating regions respecting the neighbouring countries policy of the International Visegrad Fund in the fields related to all aspects of sustainability.

The Association provides opportunities for a greater interaction and efficiency of Visegrad academic and research activities, for raising the profile of the region and strengthening the international cohesion of Central Europe as well as enabling relation to third countries, other regional groupings and international organizations.

The objectives of the association are:

$\square$ to promote cooperation among member universities in education and research, exchange of students and staff, $\square$ to exchange information, scientific knowledge and research results by publishing the international scientific journal "Visegrad Journal on Bioeconomy and Sustainable Development" and by cooperation in elaborating scientific studies related to the future development of higher education and research as well as to all aspects of sustainability,

$\square$ to provide platform for cooperation in the field of joint and double degree diplomas,

$\square$ to promote cooperation among member universities in research and education for the benefit of economy, society, peace and cultural development of the countries referred to the Association.

The original intention to act only in the Visegrad region and neighbouring regions showed to be undersized, as partners from more distant regions (eg. South East Asia, India and others) have shown interest to formalize their relationships through associations with a group of universities from Central Europe. The VUA is now open to all universities from Visegrad and other regions dealing with all aspects of sustainability. Of course, strengthening the academic and research links according to the foreign policy priorities with institutions form Central Europe, V $4+2$, Eastern Partnership and Russia, Western Balkans will remain the core interest.

The Visegrad University Association creates new opportunities and possibilities for mutual cooperation in academic education, research and science. In the near future, the Association tends to become also a member of ICA, the prestigious international Association for European Life Science Universities. The Association succeeds in creating an international platform for exchanging information, scientific knowledge and research results visible in practice on various scientific events. The VUA has created a tradition in organizing successful summer schools for students. The third year of the summer school was organized by the Slovak University of Agriculture in Nitra in cooperation with the University of Hradec Kralove and the Hamburg University of Applied Sciences. Students from the Czech Republic, Russia, Ukraine, Poland, Kazakhstan and Slovakia had an opportunity to take part in lectures on sustainable development, water sources management and Danube development strategies held by international experts.

The intention of the VUA is to educate not only successful scientists and researchers, but also potential leaders in scientific field and within our organization. This way we can continue developing the future of the VUA. Therefore, there was created the VUA Youth, which should work as a bridge between the students and the management of the VUA partner universities and create easier, more flexible and efficient communication and an inspiring space for new student ideas. The memorandum of the VUA Youth was signed during the first Visegrad scientific symposium Multifunctionality and regional development at the St. Istvan University Gödöllő and the Karoly Robert University College in Hungary. More than 100 participants from 20 countries took part at this scientific event and the best papers were awarded the Visegrad Prize. The intentions of the VUA Youth are fully consistent with the objectives of the International Visegrad Fund and the European programme Erasmus +. Multiregional representation 
of partner universities in the VUA is also a precondition for the cooperation of traditional Visegrad countries (EU) with partner universities from third countries which are in the new Erasmus + programme known as "partner countries". A long term partnership is a guarantee of systematic cooperation regardless of the region a partner university originates from.

\section{Visegrad University Association and research objectives}

Apart from educating new scientific professionals, the VUA wants to promote cooperation among member universities in research for the benefit of economy, society, peace and cultural development. At the end of April 2014, VUA representatives visited EU directorates in Brussels to discuss possibilities of cooperation. The programme of the event included a visit to the DG Research and Innovation and a meeting with the Director General, Dr. John Bell as well as the meeting at the Joint Research Centre and a discussion with the Director General. Prof. Vladimir Sucha. As the Commission's inhouse science service, the Joint Research Centre's mission is to provide EU policies with independent, evidence-based scientific and technical support throughout the whole policy cycle. Its work has a direct impact on the lives of citizens by contributing with its research outcomes to the areas that are fully in harmony with sustainability aspects of the VUA, such as healthy and safe environment, secure energy supplies, sustainable mobility and consumer health and safety (JRC, 2014). Presentations of Prof. Guido Van Huylenbroeck, the ICA President and Dr. Daniela Chiran, a representative of Steibeis Europa Centrum, provided valuable insights on presented institutions including suggestions of cooperation possibilities. One of the conclusions of meetings with representatives of the European institutions was to strengthen the visibility of the Visegrad region and the Visegrad cooperation in the European structures, the need to raise the profile of the Visegrad region and cooperating regions, which can subsequently be transformed into challenges to solve current problems of the region.

Important activity of the VUA is also the Visegrad Journal on Bioeconomy and Sustainable Development, which is published twice a year. This way there is shared scientific knowledge not only within our organization but also among scientific community worldwide. The journal focuses on issues of the Visegrad countries and cooperating regions in the area of sustainable development and bioeconomy and especially on the following topics:

Integrated Bioeconomy at global, European, regional and local levels.

$\square$ Sustainable management of natural resources and sustainable agri-food production.

$\square$ Sustainability, traceability and food security in the supply chains.

$\square$ Global sustainable development and its challenges.

$\square$ Climate change mitigation, land degradation and biodiversity.

$\square$ Green economy agenda and institutional framework.

$\square$ Renewable resources of energy.

$\square$ Rural, agricultural and forestry development.

$\square$ Entrepreneurship, international trade and innovations.

In the interest of all VUA partners, the magazine is published online in the open access system de Gruyter, while its paper version is also published in a limited edition for the needs of libraries and archiving at the VUA partner universities.

The VUA published an international textbook Food Science and Business Studies and in the terms of international cooperation, VUA has become a coorganiser of ICABR conference, which was organized last year in South Africa.

\section{Geographical and Thematic Challenges: Within and Beyond Visegrad borders}

The VUA partnership has got to the crossroad. There are many ways how to continue: the programme Horizon 2020, Danube Strategy, new exchange programmes, conferences, symposiums or summer schools. There are new exciting challenges waiting for the VUA partnership with awareness of the great responsibility for the continued existence of the VUA. Therefore, the VUA Presidency has been constantly looking for new activities that would create more opportunities for the members to cooperate on the basis of the old truth that the events based on old friendships harden and create new opportunities. The VUA Presidency proposes to create a new tradition of organizing joint scientific conferences and during annual meeting introduced a proposal of the topic for 2015 that could be of interest of the participants. The topic is Knowledge Based Bioeconomics and Sustainable Development Achievements and Challenges for $21^{\text {st }}$ Century. The proposed scientific event could be held every year in a different member university. This will create space for the partner universities and their experts to get to know each other better, to collaborate, and publish best scientific contributions in the Visegrad Journal on Bioeconomy and Sustainable Development. The bio-economy is a part of the EU 2020 Strategy for a new sustainable and social market economy. There are many documents, studies and achievements in this field and it would be very purposeful to create a VUA net of experts, dedicated to sustainability aspects and knowledge bioeconomy from different points of view.

The Bioeconomy offers Europe, but not only, a unique opportunity to address complex inter-connected challenges, while achieving economic growth. It can assist in making the transition to a more resource efficient society that relies more strongly on renewable biological resources to satisfy consumers' needs, industry demand and tackle climate change (The Bioeconomy, 2014). The bioeconomy's cross-cutting nature offers a unique opportunity to comprehensively address inter-connected societal challenges such as food security, natural resource scarcity, fossil resource dependence and climate change, while achieving sustainable economic growth (The Communication, 2012). Those problems also affect neighbouring or cooperating regions of Visegrad. All events and activities, leading to issues of sustainability aspects, knowledge-based bio-economy and innovation thanks to the existence of international academic associations can be assessed from the local, global and regional perspective. International academic and scientific cooperation and a common approach to solving these problems within the VUA ensure transfer of knowledge and best practices and common solutions.

\section{References}

INNOVATING FOR SUSTAINABLE GROWTH: A Bioeconomy for Europe. European commission. Communication from the Commission to the European Parliament, the Council, the European Economic and Social Committee and the Committee of the Regions (13. 2. 2012). Innovating for Sustainable Growth: A Bioeconomy for Europe. (Online) Retrieved (2014-11-14) from http://ec.europa.eu/research/bioeconomy/

INTERNATIONAL VISEGRAD FUND. (Online) Retrieved (2014-11-14) from http:// visegradfund.org/about/

JOINT RESEARCH CENTRE. (Online) Retrieved (2014-11-14) from https://ec.europa.eu/jrc/ en/about

\section{Contact address}

Dr. h. c. prof. Ing. Peter Bielik, PhD., Slovak University of Agriculture in Nitra, Tr. Andreja Hlinku 2, 94976, Nitra, Slovak republic, e-mail: peter.bielik@uniag.sk 